\title{
Corrigendum
}

\section{ALX receptor ligands define a biochemical endotype for severe asthma}

Isabell Ricklefs, Ioanna Barkas, Melody G. Duvall, Manuela Cernadas, Nicole L. Grossman, Elliot Israel, Eugene R. Bleecker, Mario Castro, Serpil C. Erzurum, John V. Fahy, Benjamin M. Gaston, Loren C. Denlinger, David T. Mauger, Sally E. Wenzel, Suzy A. Comhair, Andrea M. Coverstone, Merritt L. Fajt, Annette T. Hastie, Mats W. Johansson, Michael C. Peters, Brenda R. Phillips, Bruce D. Levy, and the National Heart Lung and Blood Institute's Severe Asthma Research Program- Investigators

Original citation: JCI Insight. 2017;2(14):1-14. https://doi.org/10.1172/jci.insight.93534.

Citation for this corrigendum: JCI Insight. 2018;3(6):e120932. https://doi.org/10.1172/jci.insight.120932.

Following the publication of this article, the authors became aware that there was an error in calculating the FEV1 percentage predicted, FVC percentage predicted, and FEV1/FVC percentage predicted values for subjects of mixed European descent in the SARP cohort. Correcting this error resulted in lower FEV1 and FVC percentage predicted values and slightly higher FEV1/FVC percentage predicted values - and required corrections to the spirometry data presented in Table 1, Figure 2, Figure 5F, and Supplemental Figure 2, $\mathrm{A}$ and $\mathrm{B}$. These corrections do not change the finding that lipoxin $\mathrm{A}_{4}$ levels positively correlate with lung function in asthma and that subjects with $\mathrm{SAA}^{\text {hi }} \mathrm{LXA}_{4}^{\text {lo }}$ levels have lower lung function than subjects with $\mathrm{SAA}^{\text {lo }} \mathrm{LXA}_{4}{ }^{\text {hi }}$ levels nor do they alter the conclusions of the study.

The corrected versions of Figure 2, Figure 5F, and Table 1 are below. The posted supplemental data have been updated.

The authors regret the errors. 
Table 1. Clinical characteristics and bronchoalveolar lavage leukocytes for subjects undergoing bronchoscopy ${ }^{\mathrm{A}}$

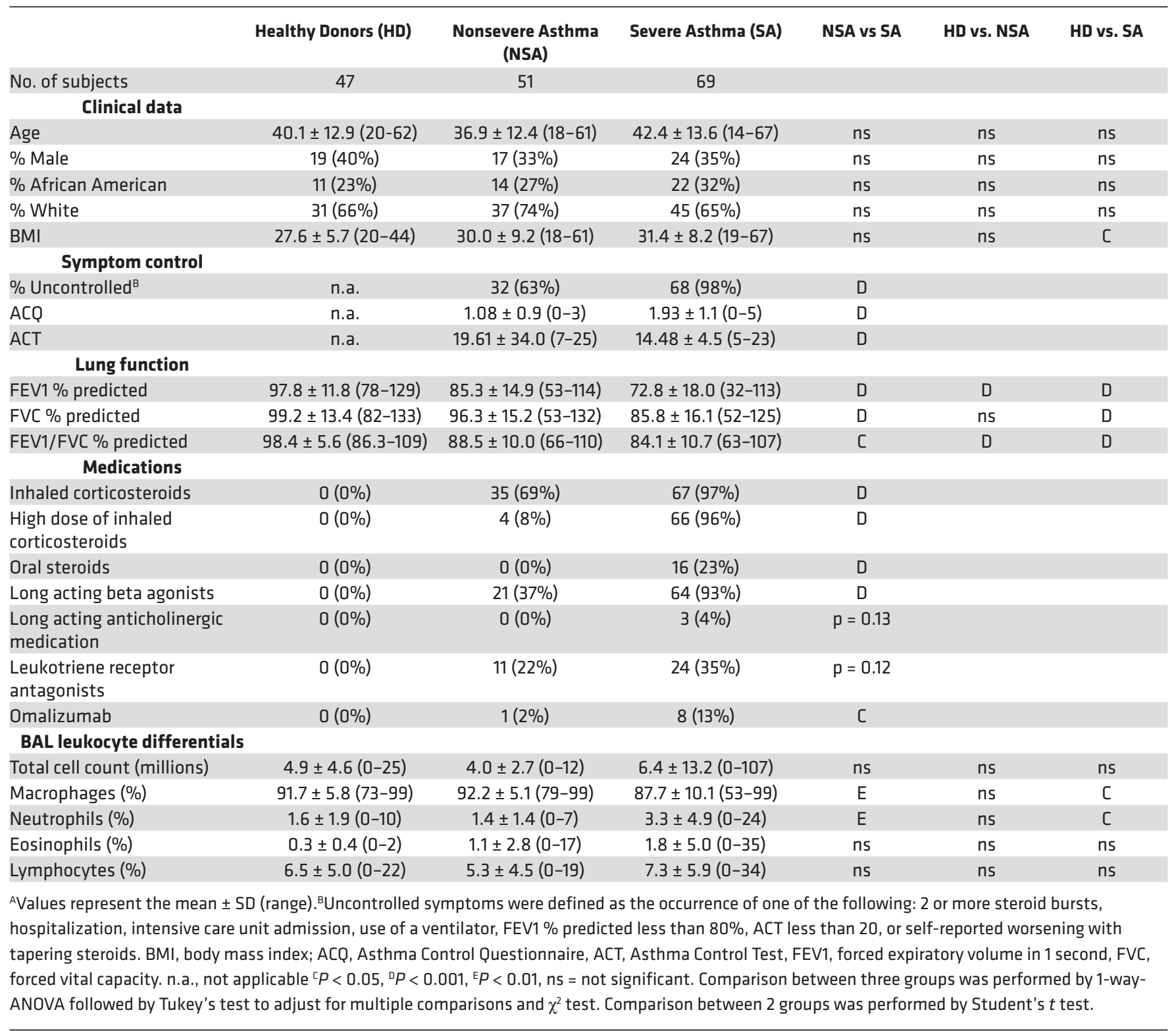




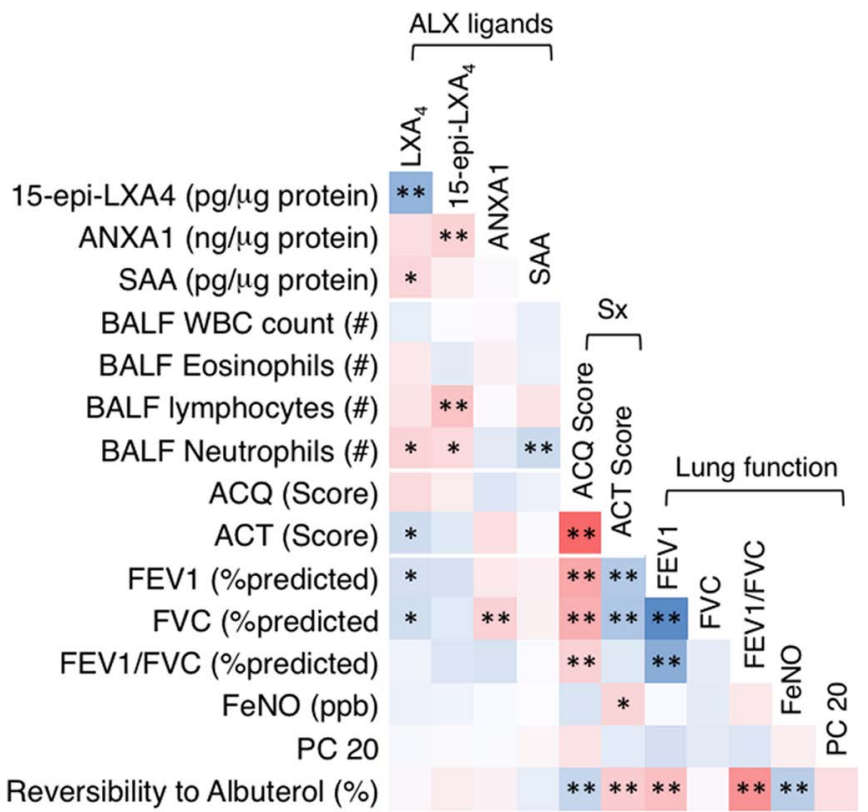

\section{$\begin{array}{llllllllllll}-0.8 & -0.6 & -0.4 & -0.2 & -0.1 & 0 & 0.1 & 0.2 & 0.4 & 0.6 & 0.8\end{array}$}

Figure 2.
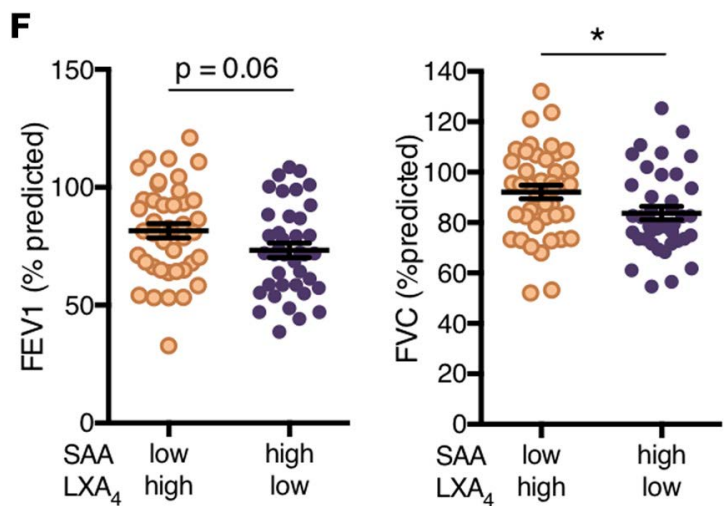

Figure 5. 